\title{
Microstructure and mechanical properties of Titanium grade 23 produced by selective laser melting
}

\author{
Piotr Nikiel ${ }^{1} \cdot$ Mirosław Wróbel $^{1} \cdot$ Stefan Szczepanik ${ }^{1} \cdot$ Michał Stępień $^{2} \cdot$ Krzysztof Wierzbanowski $^{3}{ }^{\mathbb{D}}$. \\ Andrzej Baczmański ${ }^{3}$
}

Received: 27 April 2021 / Revised: 23 August 2021 / Accepted: 8 September 2021 / Published online: 21 September 2021

(c) The Author(s) 2021

\begin{abstract}
Selective laser melted Titanium grade 23 was characterized by low porosity, relatively large surface roughness and pronounced surface texture (i.e. surface grooves orientation). The band/layer microstructure was built of mixed $\alpha$ and $\beta$ phases. The as printed structure exhibited very high compressive residual stresses with strong anisotropy (i.e., $-512 \pm 17 \mathrm{MPa}$ and $-282 \pm 14 \mathrm{MPa}$ along the laser scanning direction and along the transverse direction, respectively) and strong fiber crystallographic texture. The latter one is responsible for the anisotropy of hardness in the material. Annealing at $600{ }^{\circ} \mathrm{C}$ during four hours significantly removed residual stresses (i.e. to $-14 \pm 2.8 \mathrm{MPa}$ ) and slightly weakened the texture. Yield strength, $1120 \pm 50 \mathrm{MPa}$, and ultimate tensile strength, $1210 \pm 50 \mathrm{MPa}$, of the annealed material are significantly higher and tensile elongation, 3.9\%, lower than for commercial Titanium grade 23. Final mechanical polishing to obtain flat and relatively smooth surface induced desired compression residual stress in the subsurface (i.e., equal to about $-90 \mathrm{MPa}$ ). Low absorbed gas contents (oxygen, nitrogen, hydrogen) and low porosity of the printed material indicates the correctness of the technology and allows the printed material to be classified as meeting the requirements of ASTM standards for Titanium grade 23. Besides traditional testing techniques, the optical profilometry, X-ray analysis (texture and residual stresses measurement) and infrared absorption method were applied for the product characterization and some potential of these testing methods and usefulness in technological practice was discussed, what can be particularly interesting both to practitioners from industry and researches from scientific laboratories.
\end{abstract}

Keywords Titanium $\cdot$ Selective laser melting $\cdot$ Optical profilometry $\cdot$ X-ray diffraction $\cdot$ Microstructure $\cdot$ Hardness

\section{Introduction}

At ambient temperature and pressure, the pure titanium has the $\alpha$ phase with close-packed hexagonal structure that transforms into $\beta$ phase with body-centered cubic structure at about $890{ }^{\circ} \mathrm{C}$. The thermodynamic stability of both phases can be changed by alloying which enables to produce a heat treatable alloy with the properties which can be tailored as is the case of steels. In such a way the two phase alpha-beta titanium with nominal composition Ti-6 wt.\% Al- 4 wt.\% V can be obtained, known as Ti6Al4V, Ti-6Al-4V or Ti 6-4 alloy. This alloy was successfully introduced in the second half of the last century, e.g. [1], and now it is considered as the workhorse of the titanium industry. Two grades of the

Andrzej Baczmański

andrzej.baczmanski@fis.agh.edu.pl

1 Faculty of Metals Engineering and Industrial Computer Science, AGH University of Science and Technology, al. Mickiewicza 30, 30-059 Kraków, Poland

2 Faculty of Non-Ferrous Metals, AGH University of Science and Technology, al. Mickiewicza 30, 30-059 Kraków, Poland

3 Faculty of Physics and Applied Computer Science, AGH University of Science and Technology, al. Mickiewicza 30, 30-059 Kraków, Poland 
Ti-6Al-4 V alloy are available (i.e., grade 5 and 23). The extra low interstitials grade 23 is also known as Ti-6Al-4VELI or TAV-ELI. Significantly reduced contents of oxygen, nitrogen and iron in the grade 23 result in better ductility and fracture toughness than for the grade 5 . Thus grade 23 is commonly used for medical implants and for some other demanding applications (e.g. in aerospace industry). The alloy can be hot or cold formed but it has to be slow-speed machined using high-speed tools of the tungsten carbide (A.N.S.I. codes C1-C4) or the cobalt based ones. During machining the suitable quality of coolant flow and high feed rates are recommended. These problems lead to search for some new, economically acceptable and easier shaping techniques. Additive manufacturing (AM) techniques currently are being tried in similar cases. These techniques were initiated by trials conducted in the late 1960's at Battelle Memorial Institute, Columbus, Ohio, US and next developed by others, e.g. [2]. Selective laser melting (SLM) is one of such techniques. This technique uses a combination of laser melting and milling for creation of solid 3-dimensional objects. SLM can be characterized by a localized high heat energy input and a relatively short time of laser beam interaction with processed material. It results in rapid solidification and relatively fast cooling of the material. This can affect both the material microstructure and properties and leads to significant residual stress resulting in inacceptable distortion of the product.

The microstructure of Titanium grade 23 produced by powder selective melting using a focused laser beam, consists mainly of fine acicular $\alpha$ ' martensite, with the hexagonal close-packed ( $h c p$ ) crystal structure [3]. This phase is metastable, so, during subsequent heat treatment, it can be transformed into a mixture of the two thermodynamically stable phases, i.e., $\alpha$ and $\beta$. The resulting microstructure depends on the heat treatment temperature. Below $995{ }^{\circ} \mathrm{C}$ (i.e., the $\beta$-transus temperature) a lamellar microstructure appears with the size and volume fraction of $\alpha$ phase needles depending on temperature [3]. Above $995{ }^{\circ} \mathrm{C}$, the $\alpha$ ' phase transforms into $\beta$ one, with high temperature growth of grains. At the $\beta$-transus temperature this phase transforms into a coarse lamellar two phase microstructure (i.e., $\alpha+\beta$ ), when cooling.

Selection of laser beam scanning parameters is very important. Incorrect parameters can result in melt pool instabilities and lead to undesirable thermal stresses, segregation phenomena and a non-equilibrium phases development. The effect of different process parameters, such as laser power, layer thickness, scan speed, on density, surface quality, microstructure and mechanical properties of the product have been presented in the literature (e.g. ductility behavior was studied in [4], mechanical properties in [3] and [5] and microstructure characteristics in [6]). Different manufacturers use slightly different combinations of parameters and process efficiency is often one of the most important manufacturing factors.

Titanium alloys SLM technology was reviewed by Vrancken et al. [3], Facchini et al. [4] and Thijs et al. [6]. However, the range of research methods used for characterization of the consolidated material is usually limited. Therefore, the detailed characterization at different scales of commercially manufactured printed structure and its relation to some important properties of the product is presented in our study. The commonly used research techniques such as metallography, chemical and XRD phase analyses and mechanical testing were supplemented by optical profilometry and measurements of crystallographic texture and residual stresses (RS). The goal of this study was an attempt to solve a practical problem related to product warping but also a potential usefulness of the used techniques for industrial practice is discussed.

\section{Materials and testing methods}

\subsection{Materials}

The plate was printed from Ti-6A-14V (Grade 23) powder on a Concept laser machine, equipped with a Ron fiber laser. The spot size was $180 \mu \mathrm{m}$ and the maximum power in the continuous laser mode was $400 \mathrm{~W}$. Printing configuration is presented on Fig. 1. and characteristic sample directions are marked: SD—scanning direction, TD—-transverse direction and ND-normal direction. A continuous laser beam path was selected to form a parallel pattern scan. The beam power and scanning speed were chosen from the range of 200-370 W and of 1200-1500 mm/s, respectively. Higher values were used for the layers forming the product core (layers thickness of $50 \mu \mathrm{m}$ ) and the lower for the $25 \mu \mathrm{m}$ thick product skin. A sample of about $4 \times 70 \times 90 \mathrm{~mm}^{3}$ with parallel grooves of $2.0 \mathrm{~mm}$ depth and $10 \mathrm{~mm}$ width was cut from the product, (Fig. 2). The samples were annealed at $600{ }^{\circ} \mathrm{C}$ for $4 \mathrm{~h}$ and finally mechanically polished to obtain flat surfaces with required averaged roughness $\left(\mathrm{R}_{\mathrm{a}}\right)$ not higher than $1.5 \mu \mathrm{m}$.

\subsection{Testing techniques}

The surface profile analysis was performed on the as printed and printed and polished surfaces (Plane 1 in Fig. 2a) using a Vico NT 930 instrument. Oxygen, nitrogen and hydrogen contents were measured by Eltra $\mathrm{ONH}$ 2000 analyzer, applying the infrared absorption method for oxygen and hydrogen and thermal conductivity method for nitrogen. Nickel flux was used during oxygen and nitrogen determinations and tin flux for hydrogen analysis. Before measurements, the instrument was calibrated using the Ti 
Fig. 1 Visualization of the printed sample with a support. Laser scanning direction (SD), transverse direction (TD) and ND direction are marked. Build Plane (BP) is perpendicular to ND.


(a)

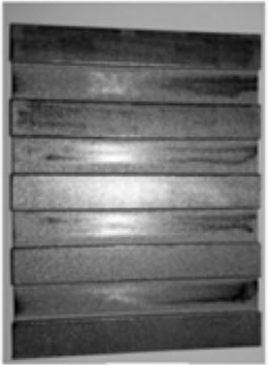

(b)



(c) (d) standard with the composition: $851 \pm 40 \mathrm{ppm}$ of oxygen, $96 \pm 15 \mathrm{ppm}$ of nitrogen and $58 \pm 3 \mathrm{ppm}$ of hydrogen. Immediately prior to sample measurements, the surface oxide layer was removed thoroughly, then the sample was cleaned in acetone for $5 \mathrm{~min}$ in an ultrasonic washer, and dried in a stream of compressed air. The material density was determined using the Archimedes' method recommended for refractory products by some standards (e.g. ASTM C20-00 [7], ASTM C134 [8], ISO 5016 [9] and ISO 5017 [10]) and applied for printed elements (e.g. [11]).
A Leica DM4000M microscope was used for metallographic examination of porosity on the polished and nonetched surfaces, with a resolution enabling detection of pores with diameters of approx. $0.1 \mu \mathrm{m}$. Then the specimens were etched (in a $50 \mathrm{ml} \mathrm{H}_{2} \mathrm{O}, 0,25 \mathrm{ml} \mathrm{HNO}_{3}$ and $5 \mathrm{ml} \mathrm{HF}$ solution) for further microstructural characterization.

A Panalytical Empyrean diffractometer was used for the $\mathrm{X}$-ray measurements using $\mathrm{Ni}$ filtered $\mathrm{Cu}$ radiation (the filter thickness was $0.02 \mathrm{~mm}$ ). A parallel Goebel mirror (length $55.3 \mathrm{~mm}$, acceptance angle $0.8^{\circ}$ ) and Soller slit (opening $0.04 \mathrm{rad}$ ) were used to collimate the incident beam. The 
same type Soller slit and the parallel plate collimator (opening $0.18^{\circ}$ ) were placed in front of the PIXcel 3D detector. $\mathrm{X}$-ray patterns were recorded from the symmetric diffraction data (2 theta in the range of $25-150^{\circ}$ ).

Le Bail full profile fit [12] and peaks positions methodology developed by Smith \& Snyder [13] were applied for the crystallographic space group tests. For lattice cell parameters determination the trial and error (TREOR) methodology [14] and Dicevol procedure developed by Boultif and Louer [15] were used. Rietveld refinement of XRD patterns was used for determination of the quantitative phase composition [16]. The methodology of Williamson and Hall [17] was applied for lattice strain determination.

To measure residual stress (RS), $\omega$-geometry and classical $\sin ^{2} \psi$ methodology were used [18]. This measurement was performed for the printing plane (Plane 1 in Fig. 2a) in directions inclined by $0^{\circ}, 90^{\circ}, 180^{\circ}$ and $270^{\circ}$ with respect to SD. The 21.3 Ti reflection was used and $\sin ^{2} \psi$ values covered the range $0-0.6$ (with step of 0.1 ).

Crystallographic texture was calculated from the pole figures $00.2,10.0,10.1,11.0,10.2$ and 10.3 measured for the printing plane (BP plane) by using the Schulz reflection methodology [19]. The WIMV procedure [20], implemented in X'Pert Texture Panalytical software, was used for orientation distribution function calculations (cf. also [21]). Lack of sample symmetry and hexagonal crystal symmetry were assumed in the calculations.

A Zwick Z250 machine tensile tests were performed for dog bone samples, according to the ASTM E8 requirements [22] at ambient conditions and at a constant rate of $5 \mathrm{~mm} /$ min. Subsequently, a Hitachi S3500N scanning electron microscope was used to study fracture surfaces.

The Vickers hardness tests under a constant load of $49.05 \mathrm{~N}$ were done on the Zwick 3212002 tester according to the requirements of the standard ASTM E92 [23]. The Berkovich nanohardness tests were carried out according to ASTM E2546 [24] and ISO 14577 [25] standards on a CSM + Instruments nanohardness tester. The load and loading/unloading rate were $60 \mathrm{mN} / \mathrm{min}$ and $120 \mathrm{mN} / \mathrm{min}$, respectively.

\section{Results and discussion}

Traces of the printing laser movement are clearly visible on the printed product surface (BP)_Figs. 3 and 4; the printed surface is undulated. The average amplitude and wavelength of the print path are approximately $36.75 \mu \mathrm{m}$ and $0.4 \mathrm{~mm}$, respectively (in Vico NT 930 instrument the vertical resolution was $3 \mathrm{~nm}$ for single measurement). The roughness of the product surface is much lower along SD than along TD (Fig. 4, Table 1). The path amplitude is close to the thickness of the printed layer, i.e. in the range of $25-50 \mu \mathrm{m}$. The above results clearly show the usefulness of the optical profilometry for microscopic characterization of the printed structures and this measurement technique can be recommended for the routine industrial practice.

The density of printed Ti-6Al-4 V, determined by Archimedes method, is $4.42(1) \mathrm{g} / \mathrm{cm}^{3}$, therefore it is the same as that reported for laser formed Titanium grade 23 [26]. This value is only slightly lower than the density of wrought alloy produced by a traditional technology $\left(4.43 \mathrm{~g} / \mathrm{cm}^{3}\right)$ [27]. This difference is in the range of experimental uncertainty, therefore only a small porosity of the printed material can be expected. This conclusion was confirmed by metallographic observations of non-etched specimens, in which only a few pores, of size below $0.1 \mu \mathrm{m}$, were detected. Kasperovich et al. reported that in Ti-6Al-4 V, produced by selective laser melting, porosity can be $0.1-3.3 \%$ (error of $0.1 \%$ ), depending on the producers printing practice [28]. The porosity of our material was estimated as smaller than about $0.2 \%$, thus it can be concluded that a good quality technology was applied for this production.

It should be added that porosity is one of the common defects resulted from SLM processes. Porosity can be directly related to the laser beam and powder interactions
Fig. 3 Printed surface profile3D view on BP (Plane 1) (a). Enlargement of a part of profile at top along SD (b)

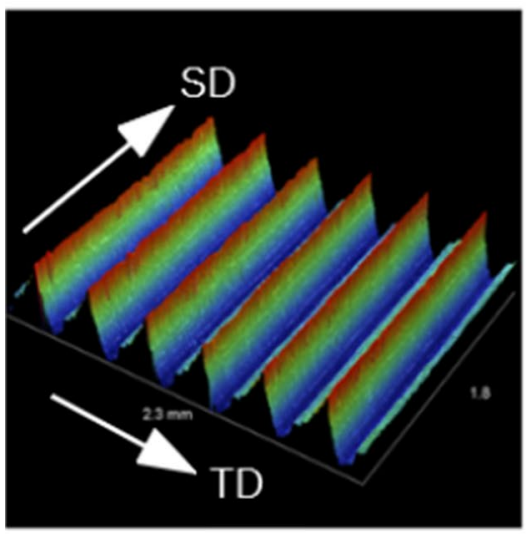

(a)

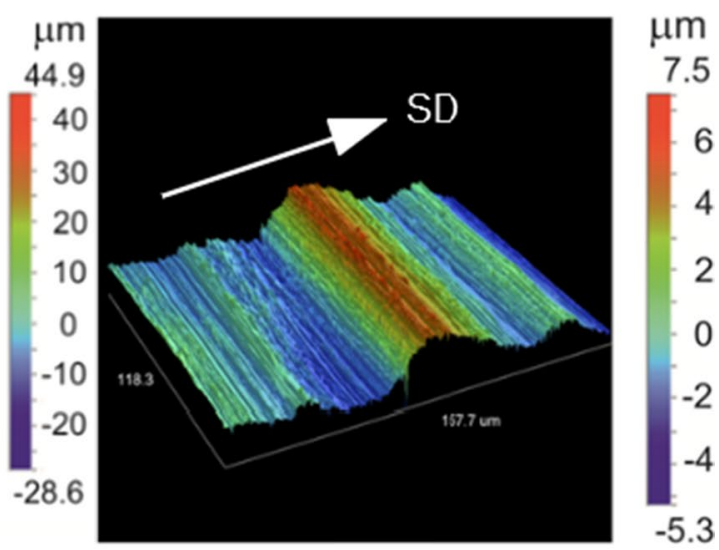

(b) 


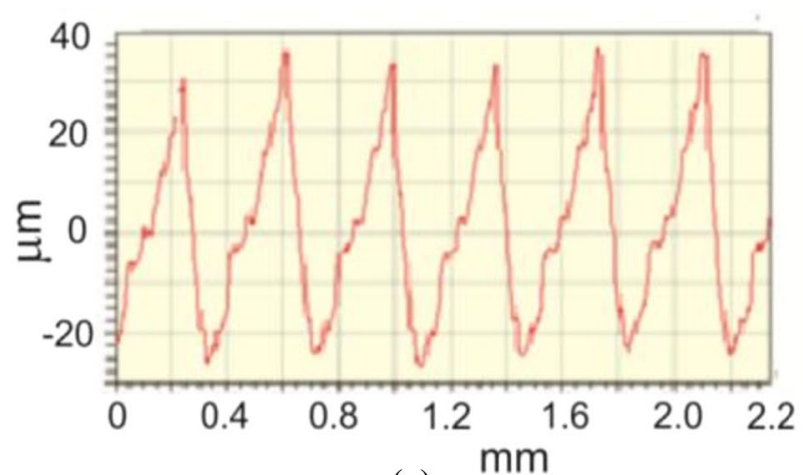

(a)

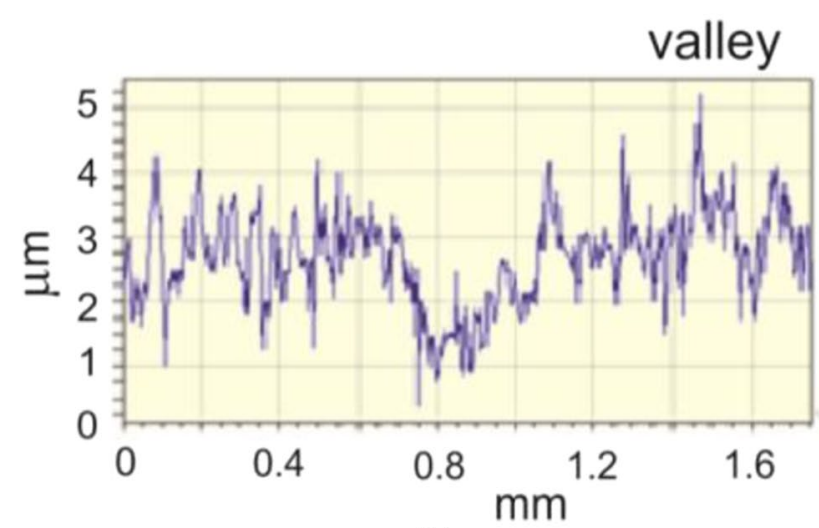

(b)



(c)

Fig. 4 Printed surface profile, 2D plot on Plane 3 along TD (a) and on Plane 2 along SD, placed at sample valley (b) and sample top positions (c). Local height is used in Figs. (b) and (c) during the process. Based on the results of Lewandowski and Seifi [29] one can conclude that in our process some optimum hatch spacing and laser power was selected to minimize porosity. However, it is worth mentioning that high porosity (60-80\%) may be required for some applications and such Ti-6Al-4V alloy can also be produced by SLM [30].

The band-microstructure cannot be observed on the surface of printed and non-etched material. However, etching revealed parallel/layer bands microstructure, as seen in Fig. 5. The bands parallel to SD are clearly visible on cross-sections parallel to Planes 1 and 2 and the microstructures observed on both cross-sections have similar character. Such microstructure is typical for material manufactured by AM technologies [31] and results from specific moving of the temperature field. Average width (i.e. size along TD, observed on plane 1) and thickness (i.e., size along $\mathrm{ND}$, observed on plane 2) of the bands are in the range $130-200 \mu \mathrm{m}$. This is close to half wavelength determining the periodicity of the bands observed with a profilometer on the printed pattern, Fig. 4a. The bands' shape and size can be more precisely determined on the cross section parallel to the plane 3. (Fig. 5c); it can be seen there that bands' cross-sections have shapes of squares with the side length of about 70-100 $\mu \mathrm{m}$ and with diagonals parallel to Plane 1 (BP) and Plane 2. The band distribution in the matrix is relatively homogeneous. This indicates a perfect selection of process parameters. Moreover, the bandwidth is much smaller than in the case of Ti-6Al-4V alloys processed by different AM techniques, which are typically in the range $260-850 \mu \mathrm{m}$ [32]. The smaller width of the band is very beneficial for mechanical properties of the printed structure.

The bands are filled with $\alpha$ phase laths colonies creating Widmanstatten type microstructure, formed inside the $\beta$ grains during cooling (a microstructure frequently observed in $\alpha+\beta$ titanium alloys [33]). However, the observed lath thickness is relatively small, which is typical for AM [30]. In Fig. 5 one can see a growth of long laths in different directions in neighboring bands. It is suggested that this type of microstructure results from minimization of the local stresses during phase transformation occurring when a region locally heated by a moving laser beam is cooled by
Table 1 The printed surface roughness parameters $(\mu \mathrm{m})$; " 0 " of height corresponds to that from Fig. $4 \mathrm{a}$

\begin{tabular}{lcccc}
\hline Parameter & All surfaces & \multicolumn{2}{c}{$\begin{array}{l}\text { Plane 3 (along } \\
\text { TD) }\end{array}$} & \multicolumn{2}{l}{ Plane 2 (along SD) } \\
\cline { 4 - 5 } & & & Valley & Top \\
\hline Root means squared roughness $\left(\mathrm{R}_{\mathrm{q}}\right)$ & 16.92 & 16.85 & 0.73 & 1.26 \\
Average roughness $\left(\mathrm{R}_{\mathrm{a}}\right)$ & 14.05 & 13.98 & 0.57 & 0.90 \\
Maximum height of the profile $\left(\mathrm{R}_{\mathrm{t}}\right)$ & 72.27 & 66.04 & 4.84 & 10.73 \\
Maximum profile peak height $\left(\mathrm{R}_{\mathrm{p}}\right)$ & & 39.03 & -22.8 & 32.31 \\
Maximum profile valley depth $\left(\mathrm{R}_{\mathrm{v}}\right)$ & & -27.1 & -27.64 & 21.58 \\
Average maximum height of the profile $\left(\mathrm{R}_{\mathrm{z}}\right)$ & 70.53 & & & \\
\hline
\end{tabular}





(a)
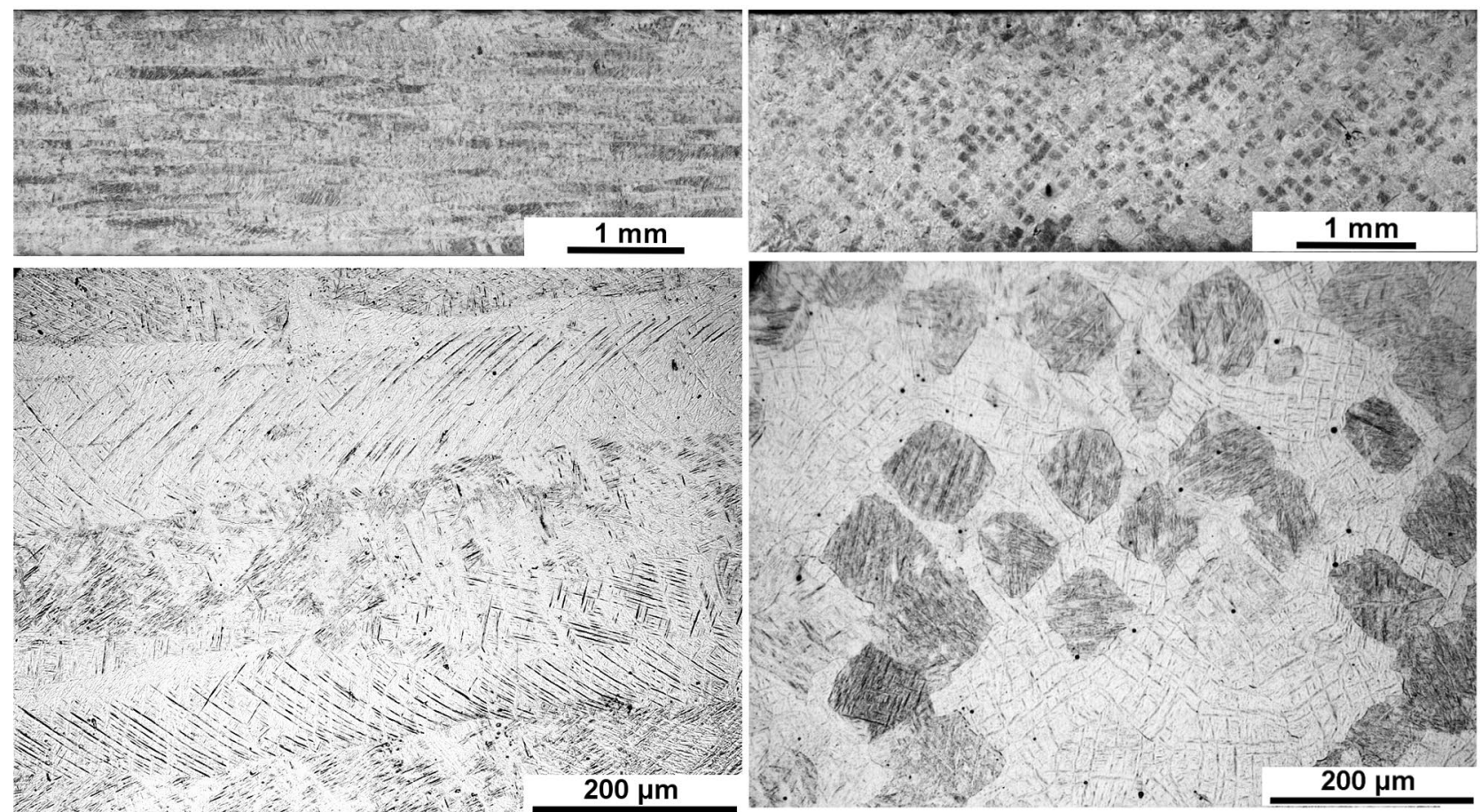

(b)

(c)

Fig. 5 Microstructure of printed and etched material shown on cross-sections parallel to: Plane 1 (a), Plane 2 (b) and Plane 3 (c)

a neighboring relatively cold material. This explanation is consistent with the thermal profile forming in Ti-6Al-4V during AM, calculated with the finite element model (see Fig. 5 in [34]) and with the type of the surface profile shown in our Fig. 3.

The microstructure of the printed and annealed material after etching is shown in Fig. 6. The bands are parallel to SD on cross-sections parallel to Planes 1 and 2. Significant changes of the microstructure after annealing at $600{ }^{\circ} \mathrm{C}$ for $4 \mathrm{~h}$ were not detected. The bands' sizes in this material are comparable to those in the initial, not annealed, material.
It should be noted that mechanical properties of two-pase $\alpha+\beta$ titanium alloys strongly depend on the microstructure shaped by the cooling rate from the $\beta$-phase range and ageing conditions as has been shown by Filip et al. [35].

The above results show that a simple density measurement is sufficient to estimate the material's porosity; additionally dye penetrant inspection and/or X-ray defectoscopy can be recommended for industrial practice as supplementary techniques. Acoustic/ultrasonic inspection may be of limited use due to a development of surface texture, especially when the surface roughness is high, as shown in 

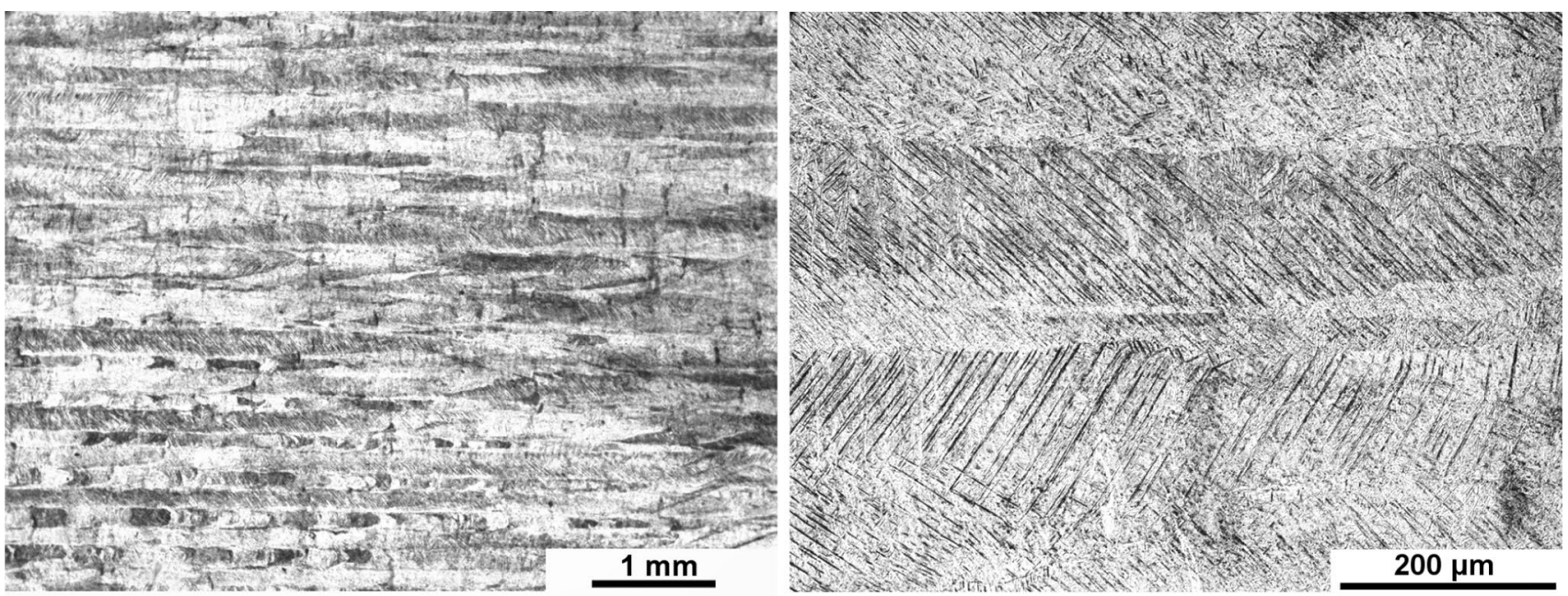

(a)
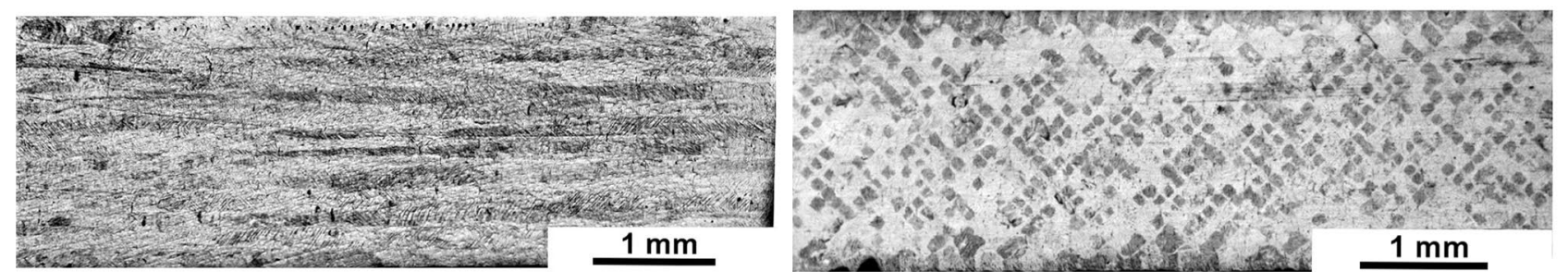

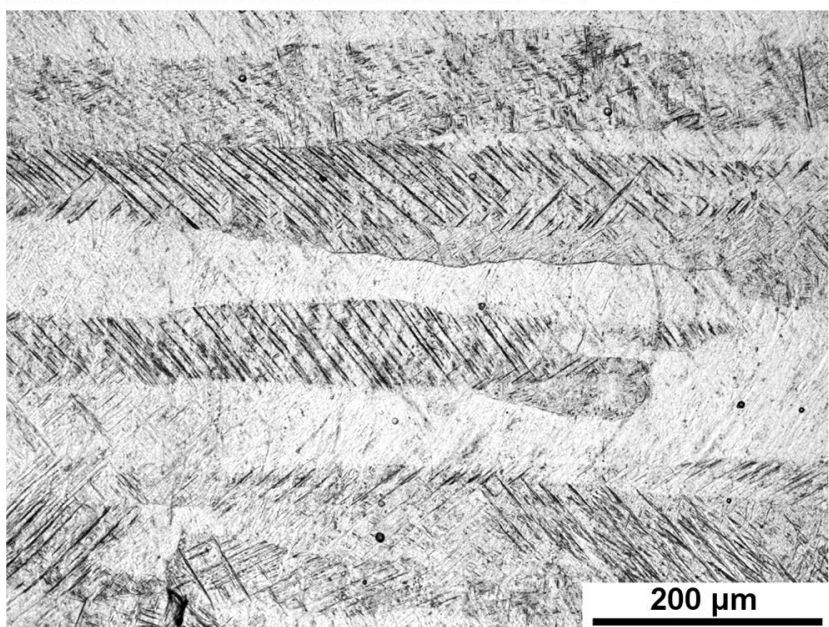

(b)

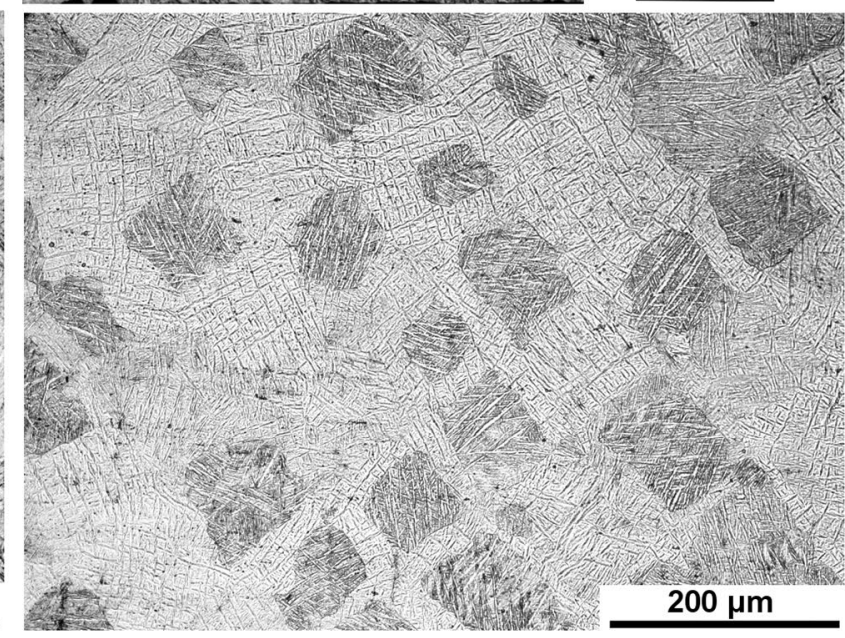

(c)

Fig. 6 Microstructure of printed and annealed material shown on cross-sections parallel to: Plane 1 (a), Plane 2 (b) and Plane 3 (c). The specimen was heat treated at $600{ }^{\circ} \mathrm{C}$ during $4 \mathrm{~h}$.

Figs. 3 and 4. On the other hand, metallographic techniques can be useful to inspect microstructure homogeneity when the parameters of SLM are selected. In such the case it can be sufficient to limit examination to the cross section perpendicular to SD (Plane 3).

X-ray diffraction (XRD) patterns are shown for the as printed and annealed materials in Fig. 7a and Fig. 7b, respectively. For both materials all diffraction peaks were identified. In the annealed material (Fig. 7b) peaks of both $\alpha$ and $\beta$ phases were found. For the diffraction pattern shown in Fig. 7b, the difference between measured and the refinement pattern is relatively small (Fig. 7c) and the fit goodness parameter (GOF) is 4.38. It means, that using Rietveld analysis [16], it was possible to estimate $\beta$ phase amount to be approximately $13 \%$ and also to determine lattice parameters of both phases (Table 2). Using integrated area for only one XRD-peak in each phase Pederson et al. [36] determined a similar phase share (i.e., approx. 10\%) for the alloy annealed at $610^{\circ} \mathrm{C}$ during $50 \mathrm{~min}$. In our research all peaks registered in the XRD pattern were used in the calculation procedure. 


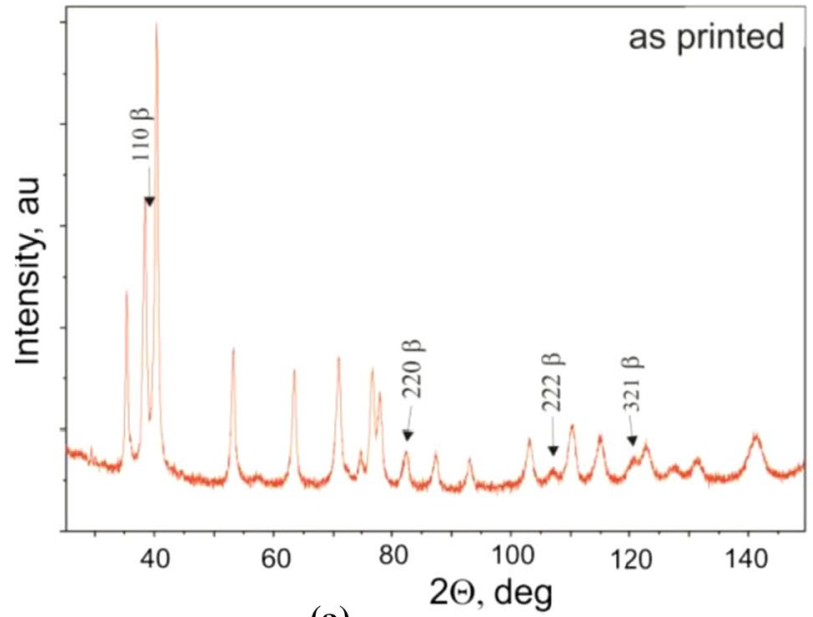

(a)
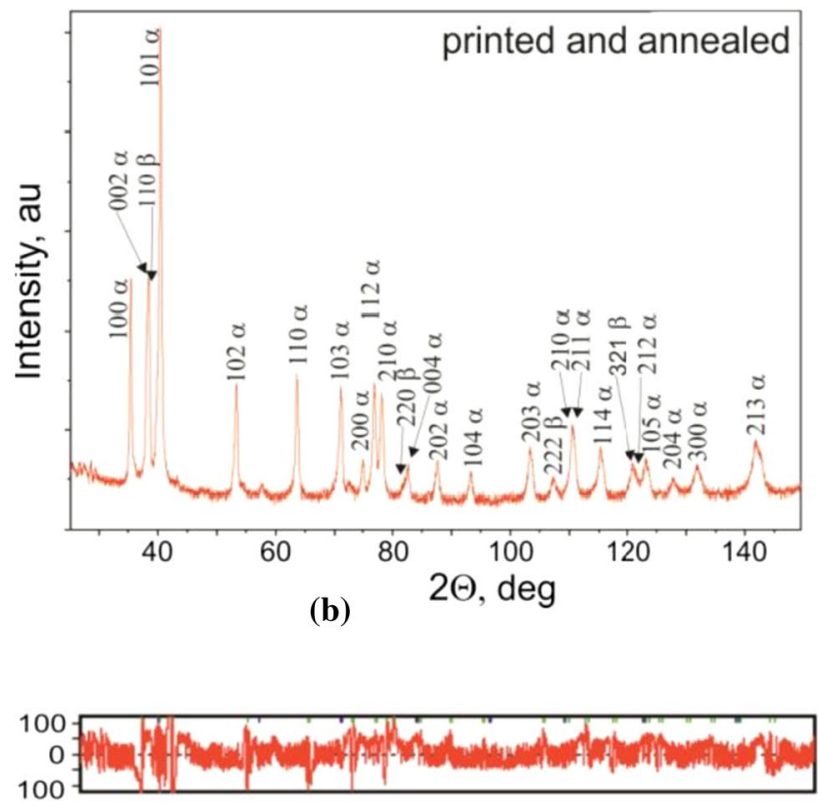

(c)

Fig. 7 X-ray diffraction patterns for the as printed material (a) and for the printed and annealed one (b). The residuals for measured and refined patterns from Fig. (b) are shown in Fig. (c)

Table 2 Crystallographic data (uncertainties of the measured lattice parameters are based on the Rietveld analysis [16] and corresponds to the GOF equal to 4.38)

\begin{tabular}{llll}
\hline & \multicolumn{2}{l}{ SLM printed } & \multicolumn{2}{l}{ SLM printed and annealed } \\
\cline { 3 - 4 } Phase & $\alpha$ & $\alpha$ & $\beta$ \\
\hline$a(\AA)$ & $2.9235(6)$ & $2.9223(1)$ & $3.3239(4)$ \\
$c(\AA)$ & $4.666(1)$ & $4.6697(2)$ & \\
$c / a$ & 1.59603 & 1.59795 & \\
$\begin{array}{l}\text { Crystallo- } \\
\text { graphic point } \\
\text { group }\end{array}$ & P63/mmc (194) & P63/mmc (194) & Im-3m (229) \\
\hline
\end{tabular}

For the as printed material $\alpha$-phase peaks in Fig. 7a are broadened and shifted from positions shown in Fig. 7b, but $\beta$ phase peaks are difficult to identify unequivocally, if any have been registered. Therefore, for this material the lattice cell refinement concerned only $\alpha$ phase and the results are collected in Table 2.

For both materials, the maximum number of counts was at least 10 000. In Fig. 7b the positions of peaks for both phases are indicated, while only peak positions expected for $\beta$ phase are marked in Fig. 7a. Some small peaks in Fig. 7a and $\mathrm{b}$ come from the titanium oxide.

In his $\mathrm{PhD}$ Pederson [31] reported that in the case of Ti6Al4V the lattice constants were: $\mathrm{a}=2.910 \pm 0.005 \AA$, $c=4.670 \pm 0.005 \AA$ for $\alpha$ phase and 3.190 $\pm 0.005 \AA$ for $\beta$ phase. The data were later published in [36]. However, the latter data are based on only one peak position and did not take into account all peaks registered in the XRD pattern, as was done by the present authors.

The P63/mmc (194) and the Im-3m (229) crystallographic point groups confirmed the presence of the phases $\alpha$ and $\beta$, respectively. For the $\alpha$ phase the results were verified both by Le Bail full profile fit [12] and peaks positions methodology developed by Smith \& Snyder [13].

Large solubility of highly electronegative elements (such as $\mathrm{N}, \mathrm{O}, \mathrm{C}, \mathrm{S}, \mathrm{F}$ and $\mathrm{Cl}$ ) occupying interstitial sites in the titanium crystal lattice is well known, since 1938 [37]. Any increase in these elements' concentration in $\alpha$ titanium would cause a lattice strain, which can be identified by diffraction peak shifts caused by a change in the $c / a$ ratio. Increase in the c/a ratio was first reported by Ehrlich [38] in 1939 and confirmed in his later paper [39].

Since some effects of different interstitials are additive, the oxygen equivalent was proposed by Ogden and Jaffe, $\mathrm{O}_{\mathrm{eq}}=\% \mathrm{O}+2 * \% \mathrm{~N}+2 / 3 * \% \mathrm{C}$, to describe the influence of $\mathrm{N}$ and $\mathrm{C}$ on strength and ductility [40]. For powders, the lattice expansion due to interstitials' absorption can be particularly pronounced for Ti-6Al-4V, as shown by Montanari et al. [41]. This effect is especially important for AM titanium, for which environmental control at each technological stage (from the powder handling and storage up to product printing and cooling) can be one of critical requirements. Interstitials entrapped in the metal after cooling to room temperature can be responsible for the increased RS and distortion. So, interstitials will be briefly discussed.

Powders of Ti-6Al-4V are usually produced as grade 5 and the extra low interstitial (ELI) grade 23. According to ASTM B348 [42] and ASTM F136 [43] requirements for the ELI grade 23, oxygen, nitrogen and hydrogen content is limited to below $0.13 \%$, below $0.03 \%$, and below $0.012 \%$, respectively. However, some manufactures offer powders with lower contents, e.g., $0.1 \% \mathrm{O}, 0.01 \% \mathrm{~N}$ and $0.003 \% \mathrm{H}$, e.g., in the Arcam product [44]. Despite this, in the AM product of Ti grade 23, oxygen and nitrogen content can 
reach $0.3 \%$ and $0.03 \%$, respectively, and on the printed surface (usually covered by an oxide layer) it can even be $3 \%$ and $0.05 \%$, respectively [45].

The gas content in the material of the present study was determined using Eltra ONH2000 instrument. The measurement for each sample was repeated 3 times and the uncertainty of the measurement was estimated with a $95 \%$ confidence level using sampling method A from [46].

The obtained contents were: $0.1193(0.0061) \%, 0.0196$ $(0.0061) \%$ and $0.0018(0.0012) \%$ for oxygen, nitrogen and hydrogen, respectively. It means, that the printed product successfully meets standard requirements of ASTM B343 and F136 for the ELI grade 23. Data on hydrogen solubility in titanium can be easily available in the literature (e.g. Ref. [47]), however, there is a difference between the total amount of hydrogen which can be absorbed in titanium and the amount which can be detected by a change in the $c / a$ ratio. Hydrogen content can easily exceed the solubility limit as a result of formation of the hydride phase, affected by rapid hydrogen diffusion [48], and hydrogen absorption can be significant already at $80^{\circ} \mathrm{C}$ as was presented by Covington at Corrosion/75 [49], published in Ref. [50] and confirmed by Wille and Davis [51]. Hydrogen effects on properties of Ti-6Al-4V have been reviewed by Veiga et al. [52]. Nitrogen solubility in titanium increases from about 2 wt. $\%$ at $500{ }^{\circ} \mathrm{C}$ up to $7.6 \mathrm{wt} . \%$ at $1083{ }^{\circ} \mathrm{C}$, e.g., [53] and [54]. Nitrogen has been shown to have the strongest strengthening effect per additive unit [55].

A chemical attraction between titanium and oxygen is the cause of substantial oxygen solubility in both phases of titanium [47]. Oxygen solubility in solid $\alpha$-titanium is 33 at. \% (i.e., about 12 wt. \%) as was reported by Murray and Wriedt [56] and compared by thermodynamic calculation by Fischer [57]. This value is significantly lower than 42 at. \% as was originally reported by Ehrlich in 1939 [38] and confirmed by him in 1941 [39]. Above $550{ }^{\circ} \mathrm{C}$ oxygen can penetrate through the surface scale into titanium and above $700{ }^{\circ} \mathrm{C}$ titanium readily absorbs atmospheric oxygen [58]. Assuming that for the annealed material used in the present study, the value of the ratio $c / a$ results only from the oxygen dissolved in the alloy matrix, the oxygen content can be expected as close to $0.2 \%$, based on the results of $\mathrm{Oh}$ et al. (see Fig. 5 in [59]). This value is significantly higher than the oxygen content in our samples, determined by thermal conductivity, $0.1193(0.0061) \%$. The difference can be related to other chemical elements dissolved in the hcp matrix and affecting $c / a$ ratio used by Oh et al. as a base of the oxygen content determination. It can be concluded that the method based on a change in the $c / a$ ratio is not precise enough to recommend it for the oxygen content determination. On the other hand, the value close to $0.2 \%$ is slightly lower than the oxygen content, ca. $0.3 \%$, measured by Kazantseva et al. [45] under the surface of the printed Ti grade 23 at depths above
$0.5 \mu \mathrm{m}$. It is worth noting that in the present measurement the penetration depth of X-rays covered the depth range of 2-5 $\mu \mathrm{m}$ (average depth $3.5 \mu \mathrm{m}$ ) below the surface, where, according to Kazantseva et al. [45], the content of oxygen and nitrogen should be constant. Moreover, the oxygen content in the tested material was relatively low (i.e., about $0.1 \%$, only). It can be summarized that nitrogen, oxygen and hydrogen contents in the investigated samples are close to the nominal contents in the powder. This indicates good control of the technological parameters.

Changes in XRD peak positions and the peak full width at half maximum (FWHM) were used to determine distortion of the crystal lattice and RS. The root mean square lattice strains were determined by the Williamson-Hall methodology, which characterizes the density of defects (especially dislocations). This method is sensitive enough to be used for tracking changes resulting from annealing of plastically deformed metals as has been proven by Dryzek and Wrobel not only for $\mathrm{Ag}, \mathrm{Au}$ and $\mathrm{Fe}$ [60] but also for $\mathrm{Nb}$ and $\mathrm{Zr}$ [61]. For the as printed specimen, the determined root mean square lattice strain was $0.4(2) \%$ and after annealing it decreased to $0.07(4) \%$, where the uncertainties are calculated on the basis of regression procedure used in Williamson-Hall method [17]. For these measurements the penetration depth of X-rays covered the depth range from 2 to $5 \mathrm{~m}$ below the surface (average depth $3.5 \mu \mathrm{m}$ ). Change in the root mean square lattice strain indicates that the high dislocation density generated in the printed material significantly decreased in the annealed sample.

Compressive or tensile RS may occur in the printed titanium and their magnitude can cover a wide range, 70-875 MPa. Such data were reported by Mishurova et al. [62], Yadroitsava and Yadroitsev [63], Yadroitsava et al. [64], Konkova et al. [65], Lim et al. [66] and others. Such high variability of RS indicates that they are significantly dependent on numerous technological parameters of the printing process. Our X-ray measurements of interplanar spacings $v s . \sin ^{2} \psi$ were carried out for the 21.3 reflection in Ti $\alpha$ phase (Fig. 8). On the basis of these measurements, RS were determined using elastic constants given by Wawra [67] and regression method presented in [68]. These data refer to an average depth of about $4 \mu \mathrm{m}$ below the printed surface (Fig. 8c). The uncertainty of the measured RS was determined on the basis of the direct relationship between the measured interplanar spacings and the regression line defined $v s . \sin ^{2} \psi$, i.e. the standard deviation of the line slope was determined, and then the error propagation method was used to estimate the stress uncertainty (for details see [68]).

It was found that compressive RS occurred in the as printed material, $-512 \pm 17 \mathrm{MPa}$ along SD, almost twice as high as the stress along TD, $-282 \pm 14 \mathrm{MPa}$, similarly to data presented by Yadroitsava et all. on An Additive Manufacturing Conference in Austin, Texas in 2015 [63] and 


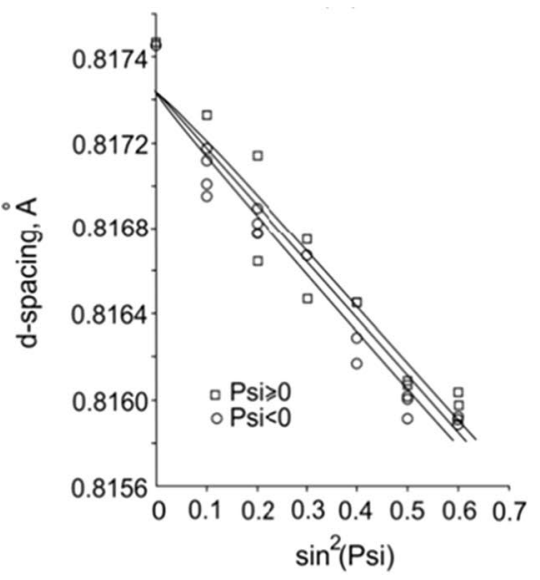

(a)



(b)

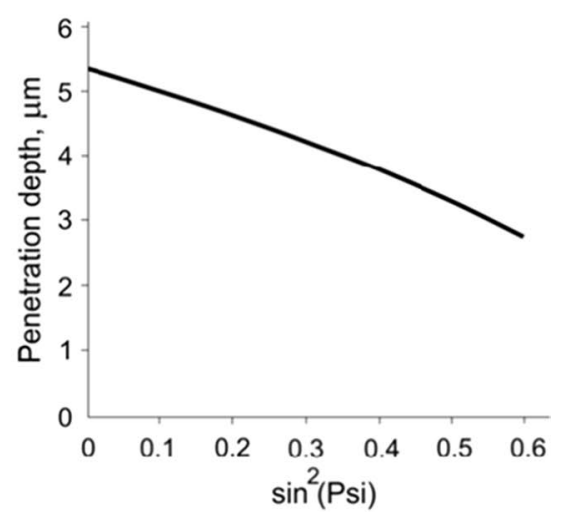

(c)

Fig. 8 Interplanar spacing for Ti- $\alpha, 21.3$ reflection $\left(2 \Theta=141.2^{\circ}\right) v s . \sin ^{2} \psi$ plots measured along TD (a) and SD (b). X-ray penetration depth $v s$. $\sin ^{2} \psi$ plot is shown in (c)

published in [64]. This relationship results partly from the wavy surface shown in Figs. 3 and 4a and is caused by relaxation of the stress in TD. Shear stresses were insignificant. It should be noted that compressive RS are desirable in some applications, because they prevent initiation and propagation of subsurface cracks during service. But the value of the compressive stress definitely should be lower (i.e., much closer to zero). The applied heat treatment $\left(600{ }^{\circ} \mathrm{C}\right.$ for $\left.4 \mathrm{~h}\right)$ significantly decreased RS (to $-14 \pm 2.8 \mathrm{MPa}$ ) and this very low value differs from that reported by Mishurova et al. [59] (treatment at $650{ }^{\circ} \mathrm{C}$ for $3 \mathrm{~h}$ ). It should be noted, however, that for some applications the compressive RS should be higher. Benedetti et al. [69] reported that the absolute values of residual stress can be radically increased in the layer of. $0.20 \mathrm{~mm}$ below the surface of SLM Titanium grade 23 after additional treatments of shot-peening, tribofinishing and even hot isostatic pressing.

Mechanical polishing of the annealed material resulted in relatively flat and smooth surface (for the $1.7 \times 2.3 \mathrm{~mm}^{2}$ surface area, the roughness parameter $\mathrm{R}_{\mathrm{a}}$ was $0.94 \mu \mathrm{m}$, so it was much below the required upper value of $1.5 \mu \mathrm{m}$. The subsurface RS was $-91.3 \pm 14 \mathrm{MPa}$. Such finish of the printed material can be beneficial for some applications, e.g. it improves resistance to fatigue. Summarizing, the present results clearly show some possibilities for RS tailoring in SLM products. Importance of this aspect should be underlined, especially at a stage of the manufacturing technology development.

Fiber crystallographic texture with relatively strong 00.2 component has been found for the as printed sample (Fig. 9a). Annealing did not change the type of the texture but weakened it by half-texture maximum dropped from 5.58 to 3.06-c.f. Figure 9a and Fig. 9b. The same type of texture was registered by neutron diffraction in
Ti-6Al-4V manufactured by SLM [70]. On the other hand, less symmetrical local texture of Ti-6Al-4 V was reported by Antonysamy et al. [71] on the basis of electron back scatter patterns for AM material, and it deviates from that measured in this study. Neikter et al. showed that texture strongly depends on the used AM method (see Fig. 7 in [70]). It can be concluded that the influence of printing parameters on crystallographic texture is to be expected and that texture measurements are useful for the industrial practice.

Average hardness of the as printed material was $387 \pm 9$ HV5 and annealing slightly reduced it to $381 \pm 6$ HV5 (uncertainties are equal to standard deviations calculated for the measurements repeated at least 20 times). Some anisotropy in the average hardness was registered and this anisotropy can be related to the crystallographic texture. For the as printed material, the average hardness in the Plane 1 (BP) was $375 \pm 3$ HV5 and it was about 17 HV5 higher in crosssections perpendicular to this plane (Table 3 ). After annealing the average hardness anisotropy decreased (Table 3), but some tendency to hardness increase with the distance from the upper surface parallel to BP is still observed (Fig. 10).

It can be noted that Benedetti et al. [69] reported a similar to our value of the average microhardness for SLM Titanium grade 23 , i.e., $380 \pm 10 \mathrm{HV}$ and being approximately constant across the sample depth. However, additional mechanical treatments like tribofinishing and shot-peening processes increased hardness in the surface layers (between 0.15 and $0.30 \mathrm{~mm}$ below the surface), while hot isostatic pressing decreased microhardness in the volume of the material.

Nanohardness results (not presented in this paper) showed insignificant differences in the average hardness of the band and the boundary region between the adjacent bands. The hardness spread can be attributed to the sizes of the $\alpha$ phase laths and can be associated both with differences in the 
Fig. 9 The orientation distribution function (ODF) for as printed specimen (a) and after annealing (b)
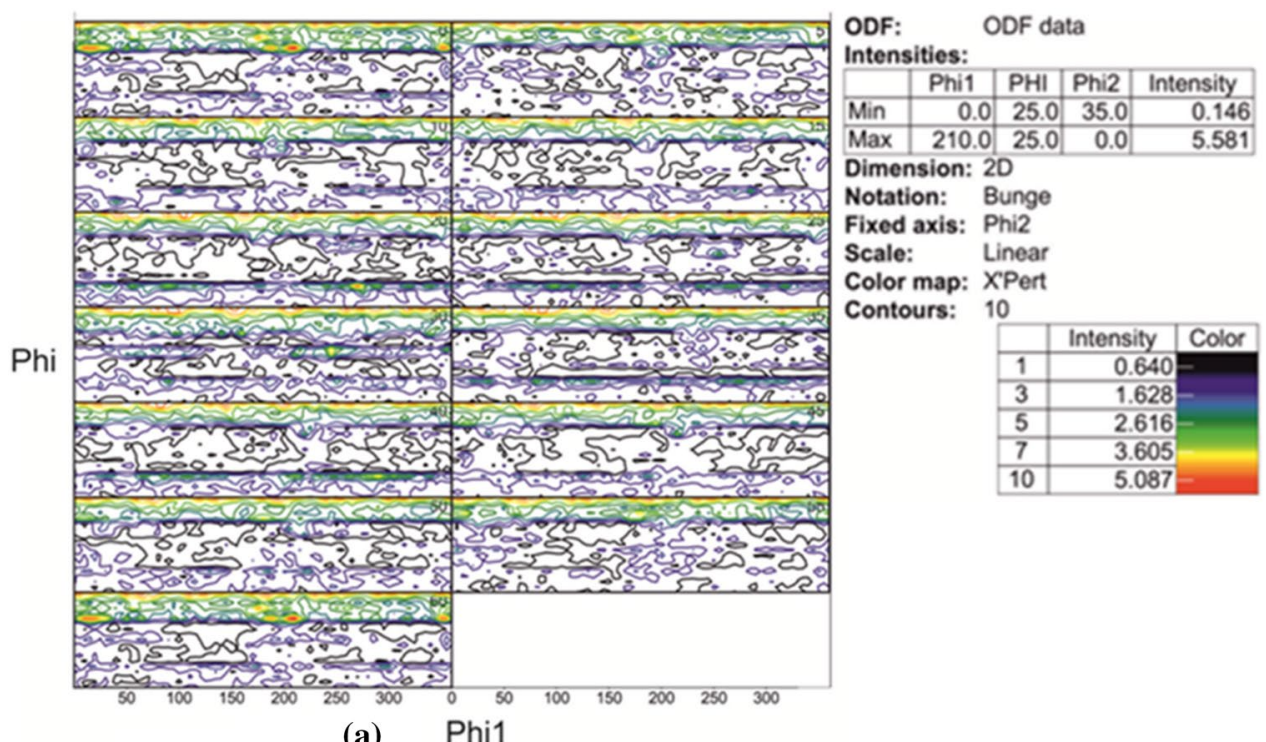

(a) Phi1
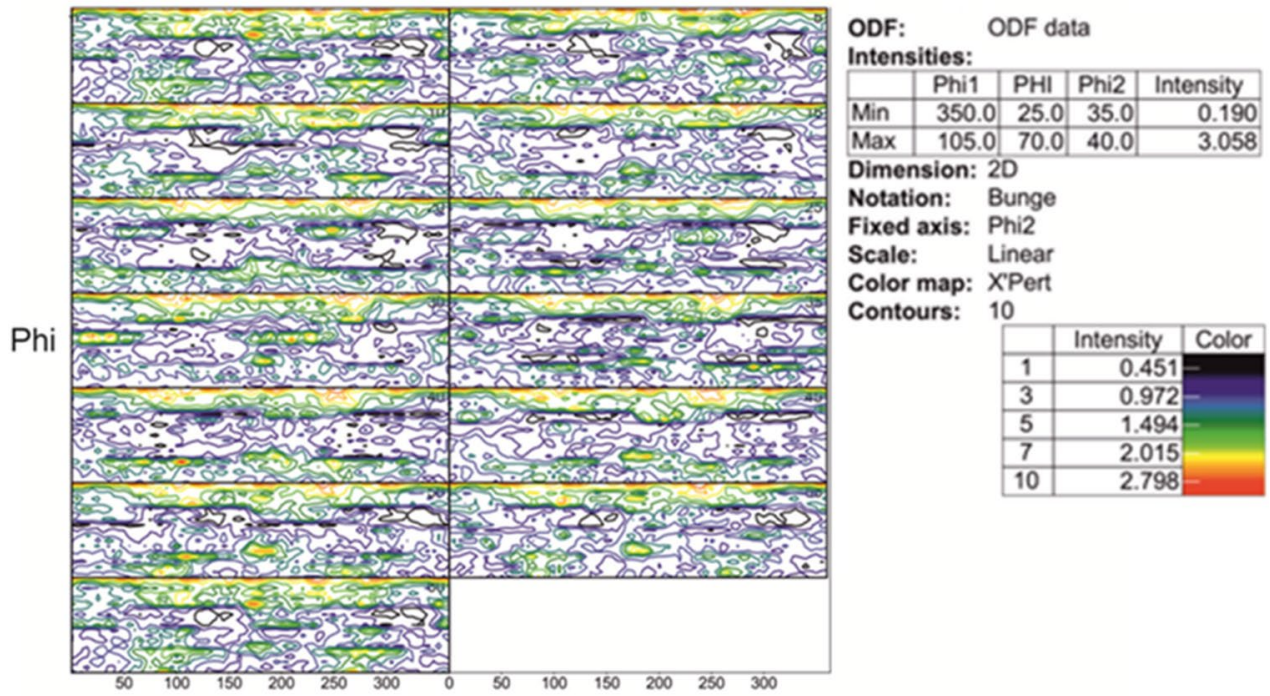

Table 3 Values of the HV5 hardness (Planes shown in Fig. 2)

\begin{tabular}{lll}
\hline Material & Site & $\begin{array}{l}\text { Average } \\
\text { hardness, } \\
\text { HV5 }\end{array}$ \\
\hline As printed & Plane 1 & $375 \pm 3$ \\
& Plane 2 & $392 \pm 2$ \\
Printed and annealed at $600{ }^{\circ} \mathrm{C}$ & Plane 3 & $393 \pm 3$ \\
during 4 h & Plane 1 & $380 \pm 3$ \\
& Plane 2 & $385 \pm 3$ \\
& Plane 3 & $379 \pm 2$ \\
\hline
\end{tabular}

hardness and the crystallographic orientations of the $\alpha$ and $\beta$ phases as was reported by Min et all. [72] and Zambaldi et all. [73] (Table 3).

Typical stress-strain curve of the annealed material is shown in Fig. 11. The determined yield strength (YS) was $1120 \pm 50 \mathrm{MPa}$, ultimate tensile strength (UTS) was $1210 \pm 50 \mathrm{MPa}$ and tensile elongation (El) was $3.9 \%$. So, strength was higher and ductility lower compared to typical materials: to SLM Titanium grade 23 (produced by 3D Systems Co.) subjected to stress relief annealing (i.e. YS $=970 \pm 30-1100 \pm 60 \mathrm{MPa}$, $\mathrm{UTS}=1070 \pm 30-1170 \pm 50 \mathrm{MPa}, \mathrm{El}=10 \pm 3-13 \pm 3 \%$ ) [25], to Ti-6Al-4V alloy produced by the classical powder metallurgy route (YS $=840-890 \mathrm{MPa}, \mathrm{El}=17-19 \%$ [74]) and to commercial grades (e.g., AZO Materials portal [27], and The METALCOLOR one [75]). However, the ductility of 


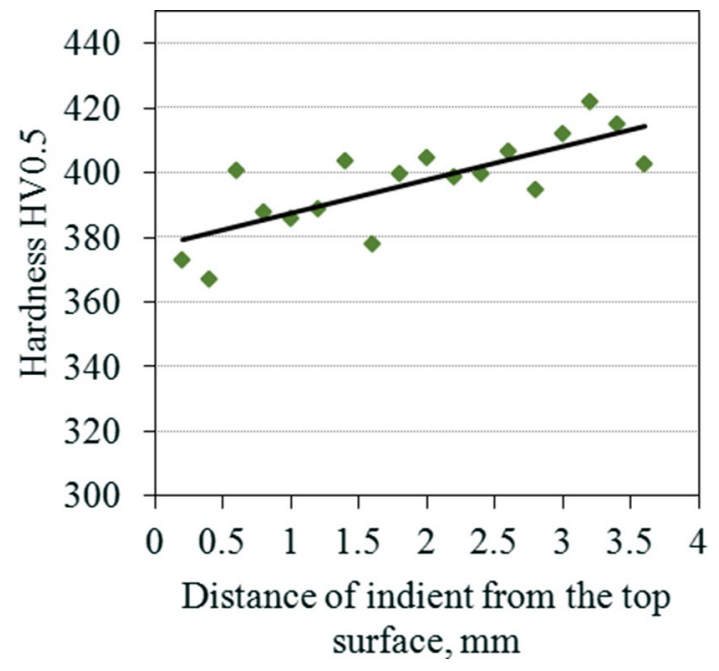

Fig. 10 Sub-surface hardness vs distance from the top surface in the annealed sample (error bars cannot be marked because measurement uncertainties are too small)

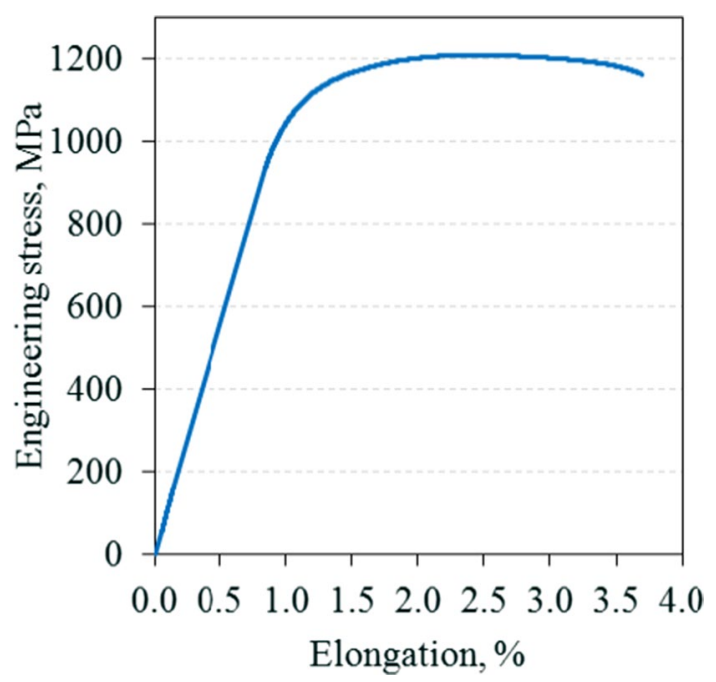

Fig. 11 The stress-strain curve of the printed material annealed at $600{ }^{\circ} \mathrm{C}$ for $4 \mathrm{~h}$. Mechanical properties: yield stress $1120 \mathrm{MPa}$, ultimate tensile strength $1210 \mathrm{MPa}$, elongation at break $3.9 \%$, reduction in area $11.7 \%$

our alloy is sufficient for numerous applications. Moreover, as was reported by Zhang et al. [76] and Wang et al. [77] the fracture toughness of SLM Ti-6Al-4V alloy can be significantly improved by dedicated processing, if needed. It should be added that a wide review of results on mechanical parameters of SLM Titanium grade 23 and SLM Titanium grade 5 (and their comparison) is done in the paper of Krakhmalev et al. [78]. The values of UTS and YS obtained for the sample studied in the present paper fit into the ranges of values from the mentioned paper, only $\mathrm{El}$ is smaller. An interesting results concerning mechanical parameters of SLM Titanium grade 23 is that UTS, YS and El parameters are higher for the horizontally built material than for the vertically built one (Rafi et al. [79]). Still another interesting relation was confirmed by $\mathrm{Xu}$ et al. [80], based on the review of literature data, for SLM Ti-6Al-4V alloy: the relation of yield strength vs. the inverse square root of average lath thickness (in the lamellar microstructure) is analogous to Hall-Petch law. In the same paper [80], also basing on the literature review, it was found that a general inverse relationship exists between yield strength (YS) and total elongation to failure (El).

The relatively low ductility revealed in the tensile test of our material corresponds to the brittle nature of the fracture surface (Fig. 12). Similar brittle fracture surfaces were also observed for additive manufactured titanium alloys-by Moridi and al. for Ti-6Al-4V alloy [81] and by He et al. [82] for $\beta$ titanium alloy. On the other hand, ductile fracture was found in Ti-6Al-4V alloy produced by the electron beam and laser melting ([83] and [77], respectively). Predominantly ductile fracture was usually observed in wrought Ti-6Al-4V [84] and [85], and in the hot isostatic pressed one [74], and a brittle failure mechanism was identified only locally [86]. A similar mixed type of fracture surface was observed by Pang et al. for SLM alloy Ti-6Al-4V [87]. In summary, one can conclude that the alloy ductility and the nature of fracture significantly depend on the microstructure. Indeed, Ojo [78] has found that fracture toughness depends on the interaction of cracks with prior $\beta$ grain boundaries and layer bands of the Ti-6Al-4V alloy produced by industrial process of the directed energy deposition additive manufacturing (i.e., laser metal deposition and laser engineered net shaping). The problem of relationship between the microstructure and plasticity of SLM Ti grade 23 alloy is addressed to future detailed research.

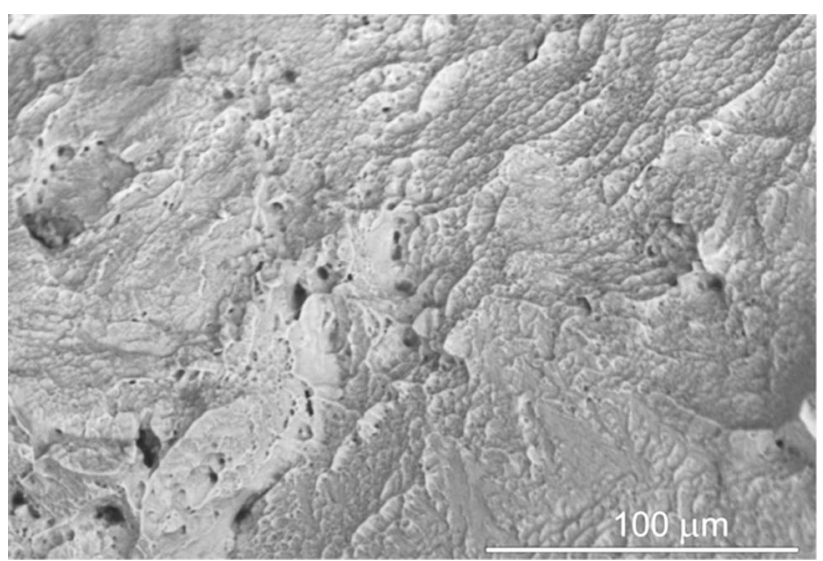

Fig. 12 Fracture surface of the material after tensile test 


\section{Conclusions}

1. Selective laser melting (SLM) resulted in a product characterized by low porosity (estimated as smaller than about $0.2 \%$ ). The gas contents, determined with a $95 \%$ confidence level, were $0.1193(0.0061) \%, 0.0196(0.0061)$ $\%$ and $0.0018(0.0012) \%$ for oxygen, nitrogen and hydrogen, respectively, which successfully meets standard requirements for the ELI Titanium grade 23 .

2. Band/layer microstructure of the product surface relief with the bands and surface grooves oriented along SD is typical for selective laser melted products. The bandwidth and thickness, formed by a mixture of $\alpha$ and $\beta$ phases, were in the range of 70-200 $\mu \mathrm{m}$.

3. Surface roughness was relatively high with average roughness $\left(\mathrm{R}_{\mathrm{a}}\right)$ and maximum height of the profile $\left(\mathrm{R}_{\mathrm{t}}\right)$ of $14.05 \mu \mathrm{m}$ and $72.27 \mu \mathrm{m}$, respectively. Such a high roughness cannot be acceptable for applications in some corrosive environments, especially when relatively high tensile stress is applied, and for some structures subjected to fatigue. In such cases, additional surface smoothing treatment is recommended.

4. Very high compressive residual stresses exhibiting strong anisotropy $(-512 \pm 17 \mathrm{MPa}$ and $-282 \pm 14 \mathrm{MPa}$ along SD and TD, respectively) were detected in the asprinted product. Moreover, relatively strong fiber crystallographic texture (with the maximum of the crystal orientation distribution function of 5.58) was characteristic for the as printed material. Four hours annealing at $600{ }^{\circ} \mathrm{C}$ almost completely removed residual stresses and weakened the texture (maximum of the crystal orientation distribution function dropped to 3.06), but the fiber character of the texture was preserved.

5. Yield strength, $1120 \pm 50 \mathrm{MPa}$, and ultimate tensile strength, $1210 \pm 50 \mathrm{MPa}$, of the annealed material are higher and tensile elongation, $3.9 \%$, lower than for commercial Titanium grade 23.

6. Mechanical polishing of the printed and annealed material produced relatively flat surface with average roughness of about $1 \mu \mathrm{m}$ and compression subsurface residual stress of about $-90 \mathrm{MPa}$.

Acknowledgements Valuable comments and suggestions of Andrew S. Wronski, emeritus Professor of the University of Bradford, UK, are appreciated. The material was provided by Oskar Nitsche from Alfred Nitsche Freden-Tool Manufacture and Technology Developing Co., Poznan, Poland -for which we are grateful.

Funding This study was funded by the AGH University of Science and Technology Work Program No. 16.16.110.663. This research project was also supported by the program "Excellence initiative-research university" for the AGH University of Science and Technology (Action 4).

\section{Declarations}

Conflict of interest All authors declare that they have no conflict of interest.

Ethical approval This article does not contain any studies with human participants or animals performed by any of the authors.

Open Access This article is licensed under a Creative Commons Attribution 4.0 International License, which permits use, sharing, adaptation, distribution and reproduction in any medium or format, as long as you give appropriate credit to the original author(s) and the source, provide a link to the Creative Commons licence, and indicate if changes were made. The images or other third party material in this article are included in the article's Creative Commons licence, unless indicated otherwise in a credit line to the material. If material is not included in the article's Creative Commons licence and your intended use is not permitted by statutory regulation or exceeds the permitted use, you will need to obtain permission directly from the copyright holder. To view a copy of this licence, visit http://creativecommons.org/licenses/by/4.0/.

\section{References}

1. Eylon D, Fujishiro S, Postans PJ, Froes FH. High temperature titanium alloys-a review. JOM. 1984;36:55-62. https://doi.org/ 10.1007/BF03338617.

2. Wohlers TT, Early Research \& Development in Rapid Prototyping, Tooling \& Manufacturing State of the Industry, Wohlers report; 2005.

3. Vrancken B, Thijs L, Kruth JP, Van Humbeeck J. Heat treatment of Ti6Al4V produced by selective laser melting: microstructure and mechanical properties. J Alloys Compd. 2012;541:177-85. https://doi.org/10.1016/j.jallcom.2012.07.022.

4. Facchini L, Magalini E, Robotti P, Molinari A, Hoges S, Wissenbach K. Ductility of a Ti-6Al-4V alloy produced by selective laser melting of prealloyed powders. Rapid Prototyp J. 2010;16:450-9. https://doi.org/10.1108/13552541011083371.

5. Facchini L, Magalini E, Robotti P, Molinari A. Microstructure and mechanical properties of Ti- $6 \mathrm{Al}-4 \mathrm{~V}$ produced by electron beam melting of pre-alloyed powders. Rapid Prototyp J. 2009;15:171-8. https://doi.org/10.1108/13552540910960262.

6. Thijs L, Verhaeghe F, Craeghs T, Van Humbeeck J, Kruth JP. A study of the microstructural evolution during selective laser melting of Ti-6Al-4V. Acta Mater. 2010;58:3303-12. https://doi.org/ 10.1016/j.actamat.2010.02.004.

7. ASTM C20-00, Standard test methods for apparent porosity, water absorption, apparent specific gravity, and bulk density of burned refractory brick and shapes by boiling water. 2015 .

8. ASTM C134-95, Standard test methods for size, dimensional measurements, and bulk density of refractory brick and insulating firebrick. 2016.

9. ISO 5016, Shaped insulating refractory products - Determination of bulk density and true porosity. 1997.

10. ISO 5017, Dense shaped refractory products - Determination of bulk density, apparent porosity and true porosity. 2013.

11. Morgan R, Sutclife CJ, O'Neil W. Density analysis of direct metal laser re-melted 316L stainless steel cubic primitives. J Mater Sci. 2004;39:1195-205. https://doi.org/10.1023/B:JMSC.0000013875. 62536.fa. 
12. Le Bail A, Duroy H, Fourquet JL. Ab-Initio structure determination of $\mathrm{LiSbWO}_{6}$ by X-ray powder diffraction. Mater Res Bull. 1988;23:447-52. https://doi.org/10.1016/0025-5408(88)90019-0.

13. Smith GS, Snyder RL. A criterion for rating powder diffraction patterns and evaluating the reliability of powder-pattern indexing. J Appl Cryst. 1979;12:60-5. https://doi.org/10.1107/S002188987 901178X.

14. Werner PE, Erikson L, Westdahl M. TREOR, A semi-exhaustive trial-and-error powder indexing program for all symmetries. J Appl Cryst. 1985;18:367-70. https://doi.org/10.1107/S002188988 5010512.

15. Boultif A, Louer D. Powder pattern indexing with the dichotomy method. J Appl Cryst. 2004;37:724-31. https://doi.org/10.1107/ S0021889804014876.

16. Rietveld HM. A profile refinement method for nuclear and magnetic structures. J Appl Cryst. 1969;2:65-71. https://doi.org/10. 1107/S0021889869006558.

17. Williamson GK, Hall WH. X-ray line broadening from filed aluminium and wolfram. Acta Met. 1953;1:22-31. https://doi.org/10. 1016/0001-6160(53)90006-6.

18. Gazzara CP. The measurement of residual stress with X-ray diffraction, Report No. MS 83-1, US Army Materials and Mechanics Research Center. Watertown, Massachusetts. 1983.

19. Schulz LG. A direct method of determining preferred orientation of a flat reflection sample using a Geiger counter X-ray spectrometer. J Appl Phys. 1949;20:1030-3. https://doi.org/10.1063/1. 1698268

20. Matthies S. On the reproducibility of the orientation distribution function of texture samples from pole figures (Ghost phenomena). Phys Stat Sol. 1979;92b:135-8. https://doi.org/10.1002/pssb. 2220920254

21. Tarasiuk J, Wierzbanowski K, Baczmański A. New algorithm of direct method of texture analysis. Cryst Res Technol. 1998;33:101-18.

22. ASTM E8, Standard test methods for tension testing of metallic materials. 2009.

23. ASTM E92, Standard test method for Vickers hardness of metallic materials. 2003.

24. ASTM E2546, Standard practice for instrumented indentation testing. 2015.

25. ISO 14577, Metallic materials- Instrumented indentation test for hardness and materials parameters. 2015.

26. LaserForm Ti Gr23(A); https://www.3dsystems.com/sites/defau 1t/files/2020-08/3d-systems-laserform-ti-gr23\%28a\%29-datasheetus-a4-2020-06-16-a-print.pdf. Accessed 07 Apr 2021.

27. Grade $23 \mathrm{Ti} 6 \mathrm{Al}$ 4V ELI Alloy (UNS R56401). 2013. http://www. azom.com/article.aspx?ArticleID=9365. Accessed 7 Apr 2021.

28. Kasperovich G, Haubrich J, Gussone J, Requena G. Correlation between porosity and processing parameters in TiAl6V4 produced by selective laser melting. Mater Des. 2016;105:160-70. https:// doi.org/10.1016/j.matdes.2016.05.070.

29. Lewandowski JJ, Seifi M. Metal additive manufacturing: a review of mechanical properties. Annu Rev Mater Res. 2016;46:151-86. https://doi.org/10.1146/annurev-matsci-070115-032024.

30. Moszybrocka J, Gapiński B, Dworak M, Skrablak G, Stwora A. The manufacturability and compression properties of the Schwarz Diamond type Ti6Al4V cellular lattice fabricated by selective laser melting. Int J Adv Manuf Technol. 2019;105:3411-25. https://doi.org/10.1007/s00170-019-04422-6.

31. Kelly SM, Kampe SL. Microstructural evolution in laser-deposited multilayer Ti-6Al-4V builds: part II. Thermal modelling Metall Mater Trans A. 2004;35:1869-79. https://doi.org/10.1007/ s11661-004-0095-7.

32. Neikter M, Akerfeld P, Pederson R, Antti ML, Sandell V. Microstructural characterization and comparison of Ti-6Al-4V manufactured with different additive manufacturing processes. Mater
Charact. 2018;143:68-75. https://doi.org/10.1016/j.matchar.2018. 02.003 .

33. Pederson R: Microstructure and phase transformation of Ti-6Al4V, Doctoral Thesis. Luleå University of Technology; 2002.

34. Wang F, Williams S, Colegrove P, Antonysamy AA. Microstructure and mechanical properties of wire and Arc additive manufactured Ti-6Al-4V. Metall Mater Trans A. 2013;44A:968-77. https://doi.org/10.1007/s11661-012-1444-6.

35. Filip R, Kubiak K, Ziaja W, Sieniawski J. The effect of microstructure on the mechanical properties of two-phase titanium alloys. J Mater Process Technol. 2003;133:84-9. https://doi.org/10.1016/ S0924-0136(02)00248-0.

36. Pederson R, Babushin O, Skystedt F, Waren R. Use of high temperature $\mathrm{x}$-ray diffractometry to study phase transitions and thermal expansion properties in Ti-6Al-4V. Mater Sci Tech-Lond. 2003;19:1533-8. https://doi.org/10.1179/026708303225008013.

37. Fast JD. Crack-free forming of zirconium and titanium. Metallwirtschaft. 1938;17:459-66.

38. Ehrlich P. Phasenverhältnisse und magnetisches Verhalten im System Titan-Sauerstoff. Z Electrochem. 1939;45:362-70.

39. Ehrlich P. Lösungen von Sauerstoff in metallischem Titan. Z Anorg Chem. 1941;247:53-64. https://doi.org/10.1002/zaac. 19412470106

40. Ogden HR, Jaffe RL. The effects of carbon, oxygen, and nitrogen on the mechanical properties of titanium and titanium alloys. TML Report No. 20, Titanium Metallurgical Laboratory. Battelle Memorial Institute, Columbus, Ohio; 1955.

41. Montanari R, Costana G, Tata ME, Testani C. Lattice expansion of Ti-6Al- $4 \mathrm{~V}$ by nitrogen and oxygen absorption. Mater Charact. 2008;59:334-7. https://doi.org/10.1016/j.matchar.2006.12.014.

42. ASTM 348, Standard Specification for Titanium and Titanium Alloy Bars and Billets.

43. ASTM F136, Standard Specification for Wrought Titanium -6Aluminum-4Vanadium ELI (Extra Low Interstitial) Alloy for Surgical Implant Applications (UNS R56401).

44. Ti6Al4V ELI Titanium Alloy; Arcam EBM system; https://www. cbmwales.co.uk/wp-content/uploads/2015/05/Arcam-Ti6Al4VELI-Titanium-Alloy.pdf; Accessed 07 Apr 2021.

45. Kazantseva N, Krakhmalev P, Yadroitsev I, Fefelov A, Merkushev A, Ilyinkh M, Vinogradova N, Ezhov I, Kurennykh T: Effect of oxygenTand nitrogen contents on the structure of the Ti-6Al-4V alloy manufactured by selective laser melting, Proceedings III International Scientific Conference: Material Science. Nonequilibrium Phase Transformations; 2017, pp. 101-103.

46. Ramsey MH, Ellison SLR (eds.): Eurachem/EUROLAB/ CITAC/ Nordtest/AMC Guide: Measurement uncertainty arising from sampling: a guide to methods and approaches Eurachem, 1st ed., 2007. ISBN 978094892626 6. Available from the Eurachem secretariat.

47. Nayak SK, Hung CJ, Sharma V, Alpay SP, Dongare AM, Brindley WJ, Hebert RJ. Insight into point defects and impurities in titanium from first principles. NPJ Comput Mater. 2018;4:1-10. https://doi.org/10.1038/s41524-018-0068-9.

48. Tal-Gutelmacher E, Eliezer D. The hydrogen embrittlement of titanium-based alloys. JOM. 2005;57:46-9. https://doi.org/10. 1007/s11837-005-0115-0.

49. Covington LC: Factors Affecting the Hydrogen Embrittlement of Titanium. Paper 59, Corrosion/75, National Association of Corrosion Engineers, Toronto; April 1975.

50. Covington LC. The influence of surface condition and environment on the hydriding of titanium. Corrosion. 1979;35:378-82. https://doi.org/10.5006/0010-9312-35.8.378.

51. Wille GW, Davis JW: Hydrogen in Titanium Alloys. Raport No. DE-AC02-77ET 52039, DOE/ET52039-2, McDonell Douglas Astronautics Company, St. Louis Division, Saint Louis, Missouri; April 1981. 
52. Veiga C, Davim JP, Loureiro AJR. Properties and applications of titanium alloys: a brief review. Rev Adv Mater Sci. 2012;32:133-48.

53. Titanium-Nitrogen (Ti-N) Phase Diagram; https://pdf4pro.com/ amp/view/titanium-nitrogen-ti-n-phase-diagram-calphad-2660ce. html. Accessed 07 Apr 2021.

54. Wriedt HA, Murray JL. The N-Ti (nitrogen-titanium) system. Bulletin of Alloy Phase Diagrams. 1987;8:378-88.

55. Jaffee RI, Campbell IE. The effect of oxygen, nitrogen, and hydrogen on iodide refined titanium. JOM. 1949;1:646-54. https://doi. org/10.1007/BF03398910.

56. Murray JL, Wriedt HA. The O-Ti(Oxygen-Titanium) System. J Phase Equilib. 1987;8:148-65.

57. Fischer E. Thermodynamic calculation of the O-Ti system. J Phase Equilib. 1997;18:338-43. https://doi.org/10.1007/ s11669-997-0060-4.

58. Bignolas JB, Bujor M, Bardolle J. A study of the early stages of the kinetics of titanium oxidation by Auger electron spectroscopy and mirror electron microscopy. Surf Sci. 1981;108:L453-9. https://doi.org/10.1016/0039-6028(81)90442-8.

59. Oh JM, Lee BG, Cho SW, Lee SW, Choi GS, Lim JW. Oxygen effects on the mechanical properties and lattice strain of Ti and Ti-6Al-4V. Met Mater Int. 2011;17:733-6. https://doi.org/10. 1007/s12540-011-1006-2.

60. Dryzek J, Wróbel M, Dryzek E. Recrystallization in severely deformed $\mathrm{Ag}, \mathrm{Au}$, and $\mathrm{Fe}$ studied by positron-annihilation and XRD methods. Phys Status Solidi B. 2016;253:2031-42. https:// doi.org/10.1002/pssb.201600280.

61. Dryzek J, Wróbel M. Observation of the recrystallization process in pure $\mathrm{Nb}$ and $\mathrm{Zr}$ using positron lifetime spectroscopy and XRD techniques. Phys Status Solidi B. 2018;255:1800051. https://doi. org/10.1002/pssb.201800051.

62. Mishurova T, Cabeza S, Artzt K, Haubrich J, Klaus M, Genzel Ch, Requena G, Bruno G. New aspects about the search for the most relevant parameters for optimization of SLM materials. Materials. 2017;10:348-62.

63. Yadroitsava I, Yadroitsev I. Residual Stress in Metal Specimens Produced by Direct Laser Sintering. Annual International Solid Freeform Fabrication Symposium - An Additive Manufacturing Conference, Austin, Texas; 2015. pp. 614-625.

64. Yadroitsava I, Grewar S, Hattingh D, Yadroitsev I. Residual stress in SLM Ti6Al4V alloy specimens. Mater Sci Forum. 2015;828829:305-10. https://doi.org/10.4028/www.scientific.net/MSF. 828-829.305.

65. Konkova TN, Rachimi S, Blackwell PL. Microstructure and residual stress in Ti-6AL-4V parts made by different additative manufacturing techniques. Poster presented at Strath Wide Research Conference. The University of Strathcyde, Glasgow; 2017.

66. Lim G, Lau K, Cheng WS, Chiang Z, Krishnan M, Ardi DT: Residual Stresses inTi-6Al-4V Parts Manufactured by Direct Metal Laser Sintering and Electron Beam Melting. BSSM 12-th International Conference on Advances in Experimental Mechanics, University of Sheffield. Sheffield; 2017.

67 Wawra H. Die Kroner-Grenzen der Elastizitatsmodulntechnisch wichtiger Werkstoffe Teil II. Zahlenwerte zur Temperaturabhangingkeit der Moduln der Elemente. Z Metallkd. 1978;69:518-23.

68. Hauk V. Structural and residual stress analysis by nondestructive methods, 1st ed. Elsevier Science, Amsterdam; 1997. ISBN: 9780444824769 , eBook ISBN: 9780080541952.

69. Benedetti M, Torresani E, Leoni M, Fontanari V, Bandini M, Pederzolli C, Potrich $\mathrm{C}$. The effect of post-sintering treatments on the fatigue and biological behavior of Ti-6Al-4V ELI parts made by selective laser melting. J Mech Behav Biomed Mater. 2017;71:295-306. https://doi.org/10.1016/j.jmbbm.2017.03.024.

70. Neikter M, Woracek R, Maimaitiyili T, Scheffzük C, Strobl M, Antti ML, Akerfeldt P, Pederson R, Bjerken C. Alpha texture variations in additive manufactured Ti-6Al-4V investigated with neutron diffraction. Addit Manuf. 2018;23:225-34. https://doi.org/ 10.1016/j.addma.2018.08.018.

71. Antonysamy AA, Meyer J, Prangnell PB. Effect of build geometry on the $\beta$-grain structure and texture in additive manufacture of Ti-6Al-4V by selective electron beam melting. Mater Charact. 2013;84:153-68. https://doi.org/10.1016/j.matchar.2013.07.012.

72. Min XH, Zhang L, Sekido K, Ohmura T, Emura S, Tsuchiya K, Tsuzaki T. Strength evolution of $\alpha$ and $\beta$ phases by nanoindentation in Ti-15Mo alloys with $\mathrm{Fe}$ and $\mathrm{Al}$ addition. Mater Sci TechLond. 2012;28:342-7. https://doi.org/10.1179/1743284711Y. 0000000052.

73. Zambaldi C, Yang Y, Bieler TR, Raabe D. Orientation informed nanoindentation of $\alpha$-titanium: indentation pileup in hexagonal metals deforming by prismatic slip. J Mater Res. 2012;27:356-67. https://doi.org/10.1557/jmr.2011.334.

74. Guo RP, Xu L, Zong BYP, Yang R. Characterization of prealloyed Ti-6Al-4V powders from EIGA and PREP process and mechanical properties of HIPed powder compacts. Acta Metall Sin Engl. 2017;30:735-44. https://doi.org/10.1007/s40195-017-0540-4.

75. Datasheet 3.7165 Ti-Grade 23 (6Al-4V ELI), METALCOLOR; http://www.metalcor.de/en/datenblatt/130/. Accessed $07 \mathrm{Apr}$ 2021.

76. Zhang H, Dong D, Su S, Chen A. Experimental study of effect of post processing on fracture toughness and fatigue crack growth performance of selective laser melting Ti-6Al-4V. Chinese J Aeronaut. 2019;32:2383-93. https://doi.org/10.1016/j.cja.2018.12.007.

77. Wang W, Xu X, Ma R, Xu G, Liu W. The influence of heat treatment on microstructures and mechanical properties of titanium alloy fabricated by laser melting deposition. Materials. 2020;13:4087. https://doi.org/10.3390/ma13184087.

78. Krakhmalev P, Fredriksson G, Yadroitsava I, Kazantseva N, du Plessis A, Yadroitsev I. Deformation behavior and microstructure of Ti6Al4V manufactured by SLM. Phys Procedia. 2016;83:77888. https://doi.org/10.1016/j.phpro.2016.08.080.

79. Rafi HK, Karthik NV, Gong H, Starr TL, Stucker BE. Microstructures and mechanical properties of Ti6Al4V parts fabricated by selective laser melting and electron beam melting. J Mater Eng Perform. 2013;22:3872-83. https://doi.org/10.1007/ s11665-013-0658-0.

80. Xu W, Brandt M, Sun S, Elambasseril J, Liu Q, Latham K, Xia K, Qian M. Additive manufacturing of strong and ductile Ti-6Al-4V by selective laser melting via in situ martensite decomposition. Acta Mater. 2015;85:74-84. https://doi.org/10.1016/j.actamat. 2014.11.028.

81. Moridi A, Demir AG, Caprio L, Hart AJ, Previtali B, Colosimo BM. Deformation and failure mechanisms of Ti-6Al-4V as built by selective laser melting. Mat Sci Eng A. 2019;768: 138456. https://doi.org/10.1016/j.msea.2019.138456.

82. He B, Li J, Cheng X, Wang HM. Brittle fracture behavior of a laser additive manufactured near- $\beta$ titanium alloy after low temperature aging. Mat Sci Eng A. 2017;699:229-38. https://doi.org/ 10.1016/j.msea.2017.05.050.

83. Mur LE, Quinones SA, Gaytan SM, Lopez MI, Rodela A, Martinez EY, Hernandez DH, Martinez E, Medina F, Wicker RB. Microstructure and mechanical behavior of Ti-6Al-4V produced by rapid-layer manufacturing, for biomedical applications. J Mech Behav Biomed Mater. 2009;2:20-32. https://doi.org/10.1016/j. jmbbm.2008.05.004.

84. Hammer JT, Plastic deformation and ductile fracture of Ti-6Al$4 \mathrm{~V}$ under various loading conditions, MS Thesis, The Ohio State University, Report No DOT/FAA/TC-TT14/2, Federal Aviation Administration, W.J. Hughes Technical Center, Aviation Research Division. Atlantic City, New Jersey 08405; 2014.

85. Ojo SA. Use of compact specimens to determine fracture toughness and fatigue crack growth anisotropy of DED additive 
manufactured Ti-6Al-4V, MS Thesis. Akron: The Acron University; 2020.

86. Bathini U, Srivatsan TS, Patnaik A, Quick T. A study of the tensile deformation and fracture behavior of commercially pure titanium and titanium alloy: influence of orientation and microstructure. J Mater Eng Perform. 2010;19:1172-82. https://doi.org/10.1007/ s11665-010-9613-5.

87. Pang Z, Liu Y, Li M, Zhu Ch, Li S, Wang Y, Wang D, Song Ch. Influence of process parameter and strain rate on the dynamic compressive properties of selective laser-melted Ti-6Al-4V alloy. Appl Phys A. 2019;125:90. https://doi.org/10.1007/ s00339-018-2359-x.

Publisher's Note Springer Nature remains neutral with regard to jurisdictional claims in published maps and institutional affiliations. 